\title{
Pneumocystis diversity as a phylogeographic tool
}

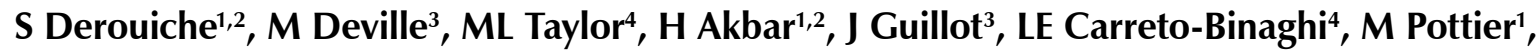 \\ EM Aliouat ${ }^{1,2}$, CM Aliouat-Denis ${ }^{1,2}$, E Dei-Cas ${ }^{2,5}$, C Demanche ${ }^{1,2 /+}$
}

1Department of Parasitology, Faculty of Biological and Pharmaceutical Sciences ${ }^{5}$ Department of Parasitology-Mycology, Faculty of Medicine, University Hospital Center, Lille North of France University, rue du Pr. Laguesse 3, BP83, 59006 Lille, France ²EA3609, IFR142, Pasteur Institute of Lille, Lille, France ${ }^{3}$ Parasitology-Mycology Service, UMR BIPAR, National School Veterinary of Alfort, Maisons-Alfort, France ${ }^{4}$ Laboratorio de Inmunología de Hongos, Department de Microbiología-Parasitología, Facultad Medicina, Universidad Nacional Autónoma de México, México, DF, México

Parasites are increasingly used to complement the evolutionary and ecological adaptation history of their hosts. Pneumocystis pathogenic fungi, which are transmitted from host-to-host via an airborne route, have been shown to constitute genuine host markers of evolution. These parasites can also provide valuable information about their host ecology. Here, we suggest that parasites can be used as phylogeographic markers to understand the geographical distribution of intra-specific host genetic variants. To test our hypothesis, we characterised Pneumocystis isolates from wild bats living in different areas. Bats comprise a wide variety of species; some of them are able to migrate. Thus, bat chorology and migration behaviour can be approached using Pneumocystis as phylogeographic markers. In the present work, we find that the genetic polymorphisms of bat-derived Pneumocystis are structured by host chorology. Therefore, Pneumocystis intra-specific genetic diversity may constitute a useful and relevant phylogeographic tool.

Key words: bats - co-evolution - ethology - host specificity - phylogeography - Pneumocystis

Recent research suggests that parasites may help to resolve the evolutionary and ecological history of their hosts. In some cases, parasites provide an additional source of information, since parasite data can better reconstruct the common history of host and their parasite (Nieberding \& Olivieri 2007). For this reason, some parasites have been recently used as phylogeographic markers (Nieberding et al. 2004, Taylor et al. 2005, Criscione et al. 2006, Nieberding \& Olivieri 2007). The Pneumocystis species have been shown to be a powerful tool in phylogenetic studies (Demanche et al. 2001, Guillot et al. 2001, 2004, Hugot et al. 2003, Aliouat-Denis et al. 2008). These eukaryotic micro-organisms, discovered by Carlos Chagas in 1909, had been described previously as enigmatic protists but are now recognised as major fungal pathogens able to provoke severe pneumonitis in severely weakened mammals. Pneumocystis pneumonia (PcP) is considered one of the most serious fungal respiratory infections to occur in immunocompromised patients, especially in human immunodeficiency virusinfected individuals (Dei-Cas 2000). Numerous aspects of the biology of these fungi still need to be clarified, notably their life cycle, which remains hypothetical (Yoshida 1989, Dei-Cas 2000). Neither the life cycle

Financial support: French Ministry of Research and Education (EA3609 Lille 2 University Quadrennial Contract, 2006-2009); ECOS-NORD, SEP-CONACYT-ANUIES-ECOS-M05-A03 (Mexico-France). + Corresponding author: christine.demanche@univ-lille2.fr

Received 25 July 2008

Accepted 9 January 2009 stage responsible for the infection nor the eventual environmental infection sources have been identified. It has been shown however, that host-to-host Pneumocystis transmission via an airborne route can occur not only between immunosuppressed laboratory rodents (Hughes 1982, Soulez et al. 1991, Walzer et al. 1977) but also between non-immunocompromised hosts, which may constitute a dynamic reservoir to the Pneumocystis species (Dumoulin et al. 2000, Chabé et al. 2004). Indeed, healthy hosts are able to radically eliminate the pathogens from their lungs but, as long as they remain infected, they can transmit Pneumocystis by an airborne route to immunocompetent hosts or to weakened members of the population, which may then develop PcP (Chabé et al. 2004, Aliouat-Denis et al. 2008).

Recently, we also know that Pneumocystis species consist of a heterogeneous group of host specific fungal parasites that have colonised a wide range of mammalian hosts. Host species-related signatures have been reported in Pneumocystis populations using genomic, karyotypic, isoenzymatic and antigenic markers (Dei-Cas et al. 1998, Aliouat-Denis et al. 2008). Cross-infection experiments showed that Pneumocystis organisms inoculated into non-specific hosts do not induce the infection (Aliouat et al. 1993, 1994, Gigliotti et al. 1993, Durand-Joly et al. 2002) and are rapidly and radically eliminated from the lungs (Aliouat-Denis et al. 2008). Indeed, on the basis of morphological, phylogenetic and experimental data, it has been demonstrated that Pneumocystis constitutes a highly diversified biological group, with numerous species (Dei-Cas et al. 1998, 2006), which are strongly hostspecific and well adapted to live inside the lungs of a diverse range of mammals (Demanche et al. 2001, Guillot et al. 2001, Hugot et al. 2003, Aliouat-Denis et al. 2008). 
It is likely that there are as many Pneumocystis species as there are mammalian host species, though some mammals may be parasitised by more than one host-specific Pneumocystis species (Aliouat-Denis et al. 2008). The close host specificity of the numerous described or still undescribed Pneumocystis species led to the hypothesis of co-evolution. Consistently, several studies compared host and Pneumocystis phylogenies and reported a strong congruence between their phylogenetic trees (Demanche et al. 2001, Guillot et al. 2001, Hugot et al. 2003). Co-phylogeny seems to be the evolutionary pattern for Pneumocystis species, which have dwelt in the lungs of mammals for more than 100 million years (Demanche et al. 2001, Guillot et al. 2001, Hugot et al. 2003, Keely et al. 2003, Aliouat-Denis et al. 2008). Since Pneumocystis species and variants constitute interesting tools to understand the phylogeny and taxonomy of their hosts, we speculated about any related possibilities they could offer. Parasites, as proxies for host genealogy, may also be useful at the phylogeographic scale (Nieberding \& Olivieri 2007).

Phylogeography is a field of research that analyses the geographical distribution of genealogical lineages and can be used to detect processes such as population subdivision, speciation events, ecological adaptation or migration routes (Emerson \& Hewitt 2005). In this study, we analysed wild bat species and their corresponding Pneumocystis. Bats display a large biodiversity, a global distribution and a flying capacity that allow some of them to migrate over short or long distances. Bats also represent a large reservoir for emerging and re-emerging pathogens (Hance et al. 2006). Thus, the bat model seems ideally suited to assess our hypothesis of using Pneumocystis diversity as a potential phylogeographic tool.

\section{MATERIALS AND METHODS}

Bats - A total of 104 lung tissue samples were obtained from wild bats in Old or New World areas. Bats were captured from December 2004-July 2007. Of the samples from Tadarida brasiliensis, 79 were collected in Tucuman (Argentina) (16) and in four states of Mexico (63) (Table I, Figure). Nine samples of Pipistrellus pipistrellus from two French regions (Table I) were obtained through the Museum d'Histoire Naturelle de Bourges (France). A total of 16 samples of Glossophaga soricina were obtained

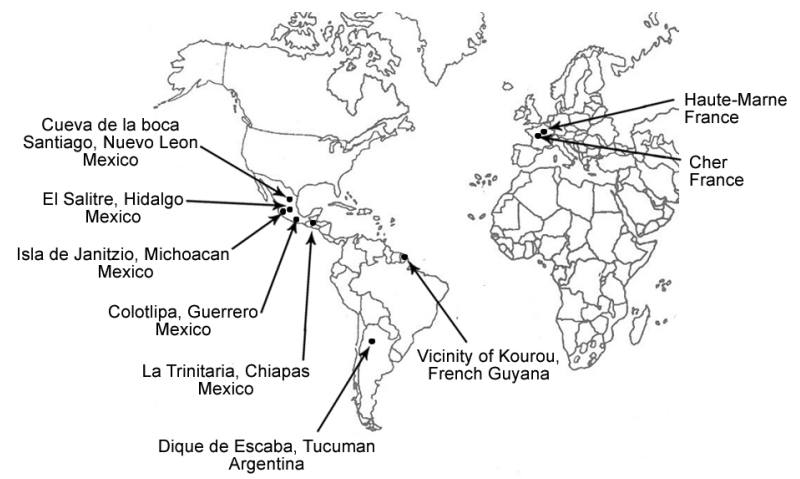

Geographical repartition of wild bat samples.

from French Guyana (in the vicinity of Kourou) (12) and Mexico (4) (Table I). Lung tissues were frozen immediately following necropsy and stored at $-20^{\circ} \mathrm{C}$.

DNA extraction - DNA extraction of all the samples was carried out using the QIAamp DNA mini kit (QIAGEN) according to the manufacturer's instructions for tissue DNA extraction. Negative controls were included in the extraction procedure to monitor for contamination and extracted DNA was stored at $-20^{\circ} \mathrm{C}$ prior to amplification.

DNA amplification and purification - Detection of Pneumocystis DNA was based on nested PCR, which amplified a portion of the mitochondrial large subunit (mtLSU) and small subunit (mtSSU) of the rRNA genes. Nested PCR at the mtLSU rRNA locus used the external primers published by Wakefield et al. (1990): pAZ102-H (5' -GTG-TAC-GTT-GCA-AAG-TAG-TC-3') and pAZ102-E (5' -GAT-GGC-TGT-TTC-CAA-GCC-CA-3'). The internal primers were pAZ102-X (5' -GTG-AAA-TAC-AAATCG-GAC-TAG-G-3') and pAZ102-Y (5' -TCA-CTTAAT-ATTAAT-TGG-GGA-GC-3') (Wakefield 1996). Nested PCR at the mtSSU rRNA locus used the following primers: pAZ112-10F (5' -GGG-AAT-TCT-AGA-CGGTCA-CAG-AGA-TCA-G-3') and pAZ112-10R (5' -GGGAAT-TCG-AAC-GAT-TAC-TAG-CAA-TCC-C-3'); then pAZ112-13RI (5' -GGG-AAT-TCG-AAG-CAT-GTTGTT-TAA-TTC-G-3') and pAZ112-14RI (5' -GGG-AATTCT-TCA-AAG-AAT-CGA-GTT-TCA-G-3') (Tsolaki et

TABLE I

Number of positive samples per bat species and geographical location (mitochondrial large subunit and small subunit of the rRNA loci merged)

\begin{tabular}{|c|c|c|c|c|c|c|c|c|c|c|c|}
\hline & \multirow[b]{2}{*}{ Argentina } & \multirow[b]{2}{*}{$\begin{array}{l}\text { French } \\
\text { Guyana }\end{array}$} & \multicolumn{5}{|c|}{ Mexico } & \multicolumn{2}{|c|}{$\begin{array}{l}\text { Museum of Natural } \\
\text { History, Bourges }\end{array}$} & \multirow{2}{*}{$\begin{array}{c}\text { Total } \\
\text { positive } \\
\text { samples }\end{array}$} & \multirow[b]{2}{*}{$\begin{array}{c}\text { Total } \\
\text { samples }\end{array}$} \\
\hline & & & Chiapas & Michoacan & Guerrero & Hidalgo & $\begin{array}{l}\text { Nuevo } \\
\text { Leon }\end{array}$ & Cher & $\begin{array}{l}\text { Haute- } \\
\text { Marne }\end{array}$ & & \\
\hline Glossophaga soricina & - & $6 / 12$ & - & - & $3 / 4$ & - & - & - & - & 9 & 16 \\
\hline Pipistrellus pipistrellus & - & - & - & - & - & - & - & $2 / 8$ & $1 / 1$ & 3 & 9 \\
\hline Tadarida brasiliensis & $8 / 16$ & - & $2 / 10$ & $2 / 6$ & - & $5 / 20$ & $19 / 27$ & - & - & 36 & 79 \\
\hline
\end{tabular}


al. 1998). The Hot Master ${ }^{\circledR}$ Taq DNA Polymerase (Eppendorf) was used for amplification of both loci. For mtLSU rRNA gene amplification, the thermocycling conditions for the first PCR round were as follows: each cycle consisted of denaturation for $30 \mathrm{~s}$ at $94^{\circ} \mathrm{C}$, annealing for $1 \mathrm{~min}$ at $50^{\circ} \mathrm{C}$ and extension for $1 \mathrm{~min}$ at $65^{\circ} \mathrm{C}$, for 30 cycles. The second round of PCR was performed with $10 \%$ of the first-round mix and the thermocycling conditions were as follows: each cycle consisted of denaturation for $30 \mathrm{~s}$ at $94^{\circ} \mathrm{C}$, annealing for $1 \mathrm{~min}$ at $55^{\circ} \mathrm{C}$ and extension for $1 \mathrm{~min}$ at $65^{\circ} \mathrm{C}$, for 30 cycles. For mtSSU rRNA gene amplification, the thermocycling conditions for the first PCR round were as follows: each cycle consisted of denaturation for $30 \mathrm{~s}$ at $94^{\circ} \mathrm{C}$, annealing for $1 \mathrm{~min}$ at $55^{\circ} \mathrm{C}$ and extension for $1 \mathrm{~min}$ at $65^{\circ} \mathrm{C}$, for 40 cycles. The second round of PCR was performed with $10 \%$ of the first-round mix and the thermocycling conditions were as follows: the first ten cycles consisted of denaturation for $30 \mathrm{~s}$ at $94^{\circ} \mathrm{C}$, annealing for $1 \mathrm{~min}$ at $52^{\circ} \mathrm{C}$ and extension for $1 \mathrm{~min}$ at $65^{\circ} \mathrm{C}$, and the following 30 cycles consisted of denaturation for $30 \mathrm{~s}$ at $94^{\circ} \mathrm{C}$, annealing for $1 \mathrm{~min}$ at $63^{\circ} \mathrm{C}$ and extension for $1 \mathrm{~min}$ at $65^{\circ} \mathrm{C}$. Negative controls were included in each experiment to monitor for possible contamination. Amplification products were purified on a $1.5 \%$ agarose gel (Trisborate-EDTA buffer) and extracted using the QIAEX II Gel Extraction kit (QIAGEN) when non-specific bands were detected. In the absence of smear or non-specific bands, the amplification products were directly purified using the Montage ${ }^{\circledR}$ PCR Centrifugal Filter Devices kit (Millipore). Purified DNA was stored at $-20^{\circ} \mathrm{C}$ prior to the sequencing reaction.

Cloning of amplified and purified products - When the amplified DNA produced a band of low intensity in the agarose gel, cloning in the bacterial system was performed using the TOPO TA Cloning ${ }^{\circledR}$ kit (Invitrogen) and the One Shot ${ }^{\mathbb{B}}$ Top 10 Chemically Competent Escherichia coli (Invitrogen). Plasmid DNA was then extracted with the Perfectprep ${ }^{\circledR}$ Plasmid Mini kit (Eppendorf), amplified with the thermocycling conditions of the first round PCR at the locus mtLSU rRNA and purified with the Montage ${ }^{\circledR}$ PCR Centrifugal Filter Devices kit (Millipore).

Sequencing of purified DNA and sequence analysis The sequencing reaction was carried out from both ends with the sets of internal primers (or primers included in the kit TOPO TA Cloning ${ }^{\circledR}$, Invitrogen, for the cloned products) and the Big Dye Terminator ${ }^{\circledR}$ v3.1 kit (Applied Biosystems). The labelled products were directly sent to GenoScreen (Pasteur Institute of Lille) and analysed on an automated DNA sequencer (3730XL DNA Analyser ${ }^{\circledR}$, Applied Biosystems). Sequences were first aligned with the software Clustal X v2.0 (Thompson et al. 1997) and then the alignment was improved manually using the software Se-Al v2.0a11 Carbon (Rambaut 2002). The aligned sequences were converted into a distance matrix (\% of differences) using the Phylogenetic Analysis Using Parsimony Program (PAUP v4.0b10, Swofford 2001).

\section{RESULTS AND DISCUSSION}

Three species of bats were included in this study: T. brasiliensis, P. pipistrellus and G. soricina. Pneumocystis DNA (mtLSU and mtSSU rRNA loci merged) was detected in 48 out of 104 samples (Table I). Amplified Pneumocystis $\mathrm{mtLSU}$ and $\mathrm{mtSSU}$ rRNA gene fragments showed host species-specific DNA sequences. In other words, all samples from $T$. brasiliensis had a similar and unique DNA sequence of Pneumocystis mtLSU and mtSSU rRNA gene fragments. The same was true for Pneumocystis DNA samples from G. soricina and P. pipistrellus. These observations confirm the high specificity of Pneumocystis organisms for their hosts. Previous studies had reported high diversity in the Pneumocystis genus and to date at least one host-specific Pneumocystis sequence has been reported from each studied mammalian host species (Mazars et al. 1997, Wakefield 1998, Demanche et al. 2001, Guillot et al. 2001, Aliouat-Denis et al. 2008).

Interestingly, DNA sequences from the Pneumocystis organisms harboured within one host species showed some genetic polymorphism in accordance with the geographical origin of the samples. For G. soricina samples, the mtLSU rRNA sequences of Pneumocystis from French Guyana (6 identical sequences) and Mexico (2 identical sequences) were different at one base position (guanine or adenine) (Table II). Since there is low variability at the mtLSU rRNA locus from G. soricinaderived Pneumocystis, our results should be confirmed by sequencing and comparison of other loci.

For the P. pipistrellus samples, some polymorphism was also observed in the Pneumocystis mtSSU rRNA sequences which diverged in less than $1 \%$ of the sequence of the P. pipistrellus population (Table III) according to the geographical origin (one sequence from Cher and one sequence from Haute-Marne, France). $P$. pipistrellus bats undergo long-distance migrations (Fleming \& Eby 2003); thus, mt rRNA polymorphisms could characterise two strains of $P$. pipistrellus-derived Pneumocystis specifically attached to two different migratory colonies of this bat species.

Comparable polymorphism was observed in the samples of T. brasiliensis, another long-distance migratory species. Two mtLSU and three mtSSU rRNA polymorphic sequences of T. brasiliensis-derived Pneumocystis were obtained. At the mtLSU rRNA locus, one unique sequence type was found in samples from the Argentinian colony (7 identical sequences), whereas a different sequence type was found in all Mexican samples (7 identical sequences). These two groups of sequences show only $1 \%$ of divergence from each other (Table II). At the mtSSU rRNA locus, one unique sequence type was found in samples from Argentina (7 identical sequences), another one in samples from Nuevo Leon (Mexico) (1 sequence) and another one in samples from Chiapas, Hidalgo and Michoacán (Mexico) (6 identical sequences). These sequences showed $0.9-1.6 \%$ divergence (Table III). Results in Nuevo Leon should obviously be confirmed with additional samples, since current results are based on only one Pneumocystis sequence. In future 
TABLE II

Matrix of distance for Pneumocystis mitochondrial large subunit of the rRNA sequences of three bats species and two outgroup species ( $P$. murina from the mouse and $P$. oryctolagi from the rabbit)

\begin{tabular}{|c|c|c|c|c|c|c|}
\hline \multirow[b]{2}{*}{ Source of rDNA } & \multicolumn{6}{|c|}{$\%$ of divergence from } \\
\hline & 1 & 2 & 3 & 4 & 5 & 6 \\
\hline 1. Pneumocystis from G. soricina (French Guyana) & - & - & - & - & - & - \\
\hline 2. Pneumocystis from G. soricina (Mexico) & 0.48 & - & - & - & - & - \\
\hline 3. Pneumocystis from T. brasiliensis (Mexico) & 14.49 & 14.03 & - & - & - & - \\
\hline 4. Pneumocystis from T. brasiliensis (Argentina) & 14.48 & 14.02 & 0.92 & - & - & - \\
\hline 5. Pneumocystis from P. pipistrellus (France) & 16.48 & 16.00 & 12.57 & 12.05 & - & - \\
\hline 6. Pneumocystis murina & 23.13 & 22.66 & 22.58 & 22.50 & 23.57 & - \\
\hline 7. Pneumocystis oryctolagi & 19.90 & 19.40 & 22.46 & 22.95 & 21.69 & 18.70 \\
\hline
\end{tabular}

TABLE III

Matrix of distance for Pneumocystis mitochondrial small subunit of the rRNA sequences of three bats species and two outgroup species (hare and rabbit)

\begin{tabular}{|c|c|c|c|c|c|c|c|}
\hline \multirow[b]{2}{*}{ Source of rDNA } & \multicolumn{7}{|c|}{$\%$ of divergence from } \\
\hline & 1 & 2 & 3 & 4 & 5 & 6 & 7 \\
\hline 1. Pneumocystis from P. pipistrellus (Haute-Marne) & - & - & - & - & - & - & - \\
\hline 2. Pneumocystis from P. pipistrellus (Cher) & 0.28 & - & - & - & - & - & - \\
\hline 3. Pneumocystis from T. brasiliensis (Nuevo Leon) & 20.06 & 20.02 & - & - & - & - & - \\
\hline 4. Pneumocystis from T. brasiliensis (Hidalgo-Chiapas-Michoacan) & 20.00 & 19.98 & 0.94 & - & - & - & - \\
\hline 5. Pneumocystis from T. brasiliensis (Argentina) & 19.75 & 19.71 & 1.26 & 1.56 & - & - & - \\
\hline 6. Pneumocystis from G. soricina (Mexico) & 19.04 & 17.78 & 14.38 & 14.03 & 14.25 & - & - \\
\hline 7. Pneumocystis f. sp. Lepus europaeus & 26.13 & 25.29 & 26.37 & 26.69 & 26.84 & 21.00 & - \\
\hline 8. Pneumocystis oryctolagi & 20.12 & 19.16 & 21.57 & 21.90 & 21.43 & 18.42 & 8.83 \\
\hline
\end{tabular}

studies, we should also use more polymorphic markers, like microsatellites, which offer a higher discriminating power, especially for characterising more accurately Pneumocystis species sub-populations linked to migratory colonies. For instance, microsatellites have already been used to characterise populations of the fungus Histoplasma capsulatum in the Americas (Carter et al. 2001).

Our results are in contrast with a 1994 study in which the frequently occurring one-base mutation of the $\mathrm{mtL}$ SU rRNA sequence could not be correlated with geography (UK, USA, Brazil and Zimbabwe) (Wakefield et al. 1994). This may be due to the fact that the portion of the mtLSU rRNA gene analysed in this study was relatively short and therefore other informative polymorphic characters may have been missed. In contrast to the Wakefield study, geography seemed to be a structuring factor to the distribution of four Pneumocystis jirovecii mtLSU rRNA genotypes isolated from HIV-infected patients in the USA (Beard et al. 2000). Likewise, a study in the UK showed a significant association between specific mtLSU rRNA genotypes of $P$. jirovecii and the patient's place of residence (Miller et al. 2005). Furthermore, several studies report that the relative proportions of $P$. jirovecii genotypes vary in accordance with the area from which the patients originated. The frequency pattern of DNA sequences from $P$. jirovecii that combine the association of three gene sequences (mtLSU rRNA, Dihydropteroate synthase and internal transcribed spacer) in specimens from Lisbon (Portugal) and Seville (Spain)) show inverted proportions (Esteves et al. 2008). In short, geographical location could therefore have a structuring role in the distribution of Pneumocystis genotypes. In the present work, the association of genotypes with migratory bat colonies suggests that there is no inter-colony transmission of Pneumocystis and that bats from different colonies do not share migratory routes.

On the whole, the present results based on two genetic markers (the mtLSU rRNA and mtSSU rRNA genes) widely used in Pneumocystis research, suggest that host species chorology could have a structuring effect on the distribution of Pneumocystis intra-specific variants. These could therefore be used as phylogeographic tools to approach the study of host species subpopulations. In fact, T. brasiliensis populations are organised into numerous colonies that could have different migratory behaviours. An attempt to clarify the migratory pathway of these different colonies was previously carried out by Russel et al. (2005). They studied bat mitochondrial DNA sequence but failed to correlate significant genetic 
polymorphism to behaviourally distinct migratory colonies. Pneumocystis intra-specific genetic polymorphisms could perhaps help to differentiate the colonies of $T$. brasiliensis and help identify their migratory pathway.

Other studies have shown the usefulness of parasite phylogeny as a mirror to host genealogy and ecology (Nieberding \& Olivieri 2007). Indeed, when parasite populations are more diversified than their host populations, gene trees of parasites can be used to infer recent migration events of infected hosts (Nieberding \& Olivieri 2007). For instance, parasite genotypes identify source populations of migratory salmon more accurately than do fish genotypes (Criscione et al. 2006). Another example is the detailed study of the comparative phylogeography of the rodent Apodemus sylvaticus and one of its specific endoparasites, the nematode Heligmosomoides polygyrus (Nieberding et al. 2004, Nieberding \& Olivieri 2007). Compared to the host tree, the parasite tree showed additional subgroups related to different geographic locations. Therefore, the phylogeographic pattern of the parasite suggested probable past differentiation and migration events that could not be detected through the study of the host itself (Nieberding \& Olivieri 2007). A recent and similar study of the geographical distribution of $A$. sylvaticus was carried out with the same set of samples (Nieberding et al. 2004, Nieberding \& Olivieri 2007), using Pneumocystis as the genetic marker (M Deville et al., unpublished observations). The same trend in phylogeographic history resulted: the host phylogeny showed two main geographical groups (Western Europe and Italy-Balkans) while the parasite phylogeny showed the same main groups but also many regional subgroups, suggesting past migration events of the host. Thus, these results support our hypothesis of using Pneumocystis as a potential phylogeographic tool. Furthermore, another pathogenic fungus, $H$. capsulatum, was also studied in T. brasiliensis bats (Taylor et al. 2005). Taylor et al. (2005) detected a pattern of molecular differences in accordance to the geography origin of $H$. capsulatum isolated from infected bats that could be used as a tool to monitor the distribution of the fungus and, thus, its host in the nature. These results support our data and suggest that such pathogenic fungi are a robust phylogeographic marker.

Finally, to be a good marker at a phylogenetic or phylogeographic scale, a parasite must share a common history with its host. One of the determining factors is a strong interaction between the host and the parasite. The strength of the host-parasite interaction depends on three parasitic traits: host specificity, presence or absence of intermediate hosts and presence or absence of a free-living phase (Nieberding \& Olivieri 2007). The lack of a free-living phase increases the dependence of the parasite on its host, as parasite migration is then exclusively limited to host movements (Nieberding \& Olivieri 2007). Thus, we can say that Pneumocystis species have a really intimate interaction with their hosts, since it has close host specificity and well documented co-evolution and co-speciation. In addition, Pneumocystis species do not have intermediate hosts and, most likely, no environmental stage. In fact, their very close host specificity and their fine adaptation to the alveolar microenvironment (Dei-Cas 2000, Dei-Cas et al. 2004, Aliouat-Denis et al. 2008) seems contradictory, or even incompatible, with any ability to multiply and survive outside their host. Furthermore, Pneumocystis populations seem to be more diversified than their host populations, as to be expected of parasites that can be used as proxies at the phylogeographic scale (Nieberding \& Olivieri 2007). All these features provide further support to our hypothesis.

In conclusion, the genetic variability of Pneumocystis that we observed in bats from distinct species or from distinct geographical areas supports our hypothesis that Pneumocystis genetic polymorphisms provide useful and relevant phylogeographic markers of host chorology. Our results validate the use of Pneumocystis as a powerful tool in phylogenetic and phylogeographic studies.

\section{ACKNOWLEDGEMENTS}

To Leonardo J. López and Alejandro Gómez Nisino, from the Instituto de Ecología, UNAM, for their help to access several Mexican caves, bat captures and taxonomic determination, to the extraordinary help of Dr. Rubén Bárquez, from the Instituto Lillo, to access the Dique Escaba, San Miguel de Tucumán, Tucumán, Argentina, and to Michèle Lemaire and Laurent Arthur (Museum of Natural History, Bourges, France), for providing lung tissue samples from wild bats. Haroon AKBAR is on the "Overseas Scholarship Scheme for France" by HEC, Islamabad, Pakistan.

\section{REFERENCES}

Aliouat-Denis CM, Chabé M, Demanche C, Aliouat EM, Viscogliosi E, Guillot J, Delhaes L, Dei-Cas E 2008. Pneumocystis species: co-evolution and pathogenic power. Infect Genet Evol, 8: 708-726.

Aliouat EM, Mazars E, Dei-Cas E, Cesbron JY, Camus D 1993. Intranasal inoculation of mouse, rat or rabbit-derived Pneumocystis to SCID Mice. J Protozool Res 3: 94-98.

Aliouat EM, Mazars E, Dei-Cas E, Delcourt P, Billault P, Camus D 1994. Pneumocystis cross infection experiments using SCID mice and nude rats as recipients hosts showed strong host specificity. J Eukaryot Microbiol 41 (Suppl.): 71S.

Beard CB, Carter JL, Keely SP, Huang L, Pieniazek PJ, Moura INS, Roberts JM, Hightower AW, Bens MS, Freeman AR, Lee S, Stringer JR, Duchin JS, del Rio C, Rimland D, Baughman RP, Levy DA, Dietz VJ, Simon P, Navin TR 2000. Genetic variation in Pneumocystis carinii isolates from different geographic regions: Implications for transmission. Emerg Infect Dis 6: 265-272.

Carter DA, Taylor JW, Dechairo B, Burt A, Koenig GL, White TJ 2001. Amplified single-nucleotide polymorphisms and a (GA) (n) microsatellite marker reveal genetic differentiation between populations of Histoplasma capsulatum from the Americas. Fungal Genet Biol 34: 37-48.

Chabé M, Dei-Cas E, Creusy C, Fleurisse L, Respaldiza N, Camus D, Durand-Joly I 2004. Immunocompetent hosts as a reservoir of Pneumocystis organisms: histological and RT-PCR data demonstrate active replication. Eur J Clin Microbiol Infec Dis 23: 89-97.

Chagas C 1909. Nova tripanozomiazaea humana. Mem Inst Oswaldo Cruz 1: 159-218.

Criscione CD, Cooper B, Blouin MS 2006. Parasite genotypes identify source populations of migratory fish more accurately than fish genotypes. Ecology 87: 823-828. 
Dei-Cas E 2000. Pneumocystis infections: the iceberg? Med Mycol 38 (Suppl. I): 23-32.

Dei-Cas E, Aliouat EM, Cailliez JC 2004. Cellular structure. In PD Walzer, MT Cushion (eds.), Pneumocystis pneumonia, 3rd ed., Marcel Dekker Inc, New York, p. 61-94.

Dei-Cas E, Chabé M, Moukhlis R, Durand-Joly I, Aliouat EM, Stringer JR, Cushion M, Noël C, Sybren de Hoog G, Guillot J, Viscogliosi E 2006. Pneumocystis oryctolagi sp. nov., an uncultured fungus causing pneumonia in rabbits at weaning: review of current knowledge and description of a new taxon on genotypic, phylogenetic and phenotypic bases. FEMS Microbiol Rev 30: 853-871.

Dei-Cas E, Mazars E, Aliouat EM, Nevez G, Cailliez JC, Camus D 1998. The host specificity of Pneumocystis carinii. J Med Mycol 8: 1-6.

Demanche C, Berthelemy M, Petit T, Polack B, Wakefield AE, DeiCas E, Guillot J 2001. Phylogeny of Pneumocystis carinii from 18 primate species confirms host specificity and suggests coevolution. J Clin Microbiol 39: 2126-2133.

Dumoulin A, Mazars E, Seguy N, Gargallo-Viola D, Vargas S, Cailliez JC, Aliouat EM, Wakefield AE, Dei-Cas E 2000. Transmission of Pneumocystis carinii disease from immunocompetent contacts of infected hosts to susceptible hosts. Eur J Clin Microbiol Infect Dis 19: 671-678.

Durand-Joly I, Aliouat EM, Recourt C, Guyot K, François N, Wauquier M, Camus D, Dei-Cas E 2002. Pneumocystis carinii f. sp. hominis is not infectious for SCID mice. J Clin Microbiol 40: 1862-1865.

Emerson BC, Hewitt GM 2005. Phylogeogaphy. Curr Biol 15: R367-371.

Esteves F, Montes-Cano MA, de la Horra C, Costa MC, Calderón EJ, Antunes F, Matos O 2008. Pneumocystis jirovecii multilocus genotyping profiles in patients from Portugal and Spain. Clin Microbiol Infect 14: 356-362.

Fleming TH, Eby P 2003. Ecology of bat migration. In TH Kunz, MB Fenton (eds.), Bat ecology, University of Chicago Press, Chicago, p. $156-208$.

Gigliotti F, Harmsen AG, Haidaris AG, Haidaris PJ 1993. Pneumocystis carinii is not universally transmissible between Mammalian species. Infect Immun 61: 2886-2890.

Guillot J, Demanche C, Hugot JP, Berthelemy M, Wakefield AE, Dei-Cas E, Chermette R 2001. Parallel phylogenies of Pneumocystis species and their mammalian hosts. J Eukaryot Microbiol 48 (Suppl.): 113S-115S.

Guillot J, Demanche C, Norris K, Wildschutte H, Wanert F, Berthelemy M, Tataine S, Dei-Cas E, Chermette R 2004. Phylogenetic relationships among Pneumocystis from Asian macaques inferred from mitochondrial rRNA sequences. Mol Phylogenet Evol 31: 988-996.

Hance P, Garnotel E, Morillon M 2006. Chiroptères et zoonoses, une émergence sur les cinq continents. Med Trop (Mars) 66: 119-124.

Hugot JP, Demanche C, Barriel V, Dei-Cas E, Guillot J 2003. Phylogenetic systematics and evolution of primate-derived Pneumocystis based on mitochondrial or nuclear DNA sequence comparison. Syst Biol 52: 735-744.

Hugues WT 1982. Natural mode of acquisition for de novo infection with Pneumocystis carinii. J Infect Dis 172: 842-848.
Keely SP, Fischer JM, Stringer JR 2003. Evolution and speciation of Pneumocystis. J Eukaryot Microbiol 50 (Suppl.): 624S-626S.

Mazars E, Guyot K, Fourmaintraux S, Renaud F, Pétavy F, Camus D, Dei-Cas E 1997. Detection of Pneumocystis in European wild animals. J Eukaryot Microbiol 44 (Suppl.): 39S.

Miller RF, Lindley AR, Copas A, Ambrose HE, Davies RJO, Wakefield AE 2005. Genotypic parathion in Pneumocystis jirovecii isolaties in Britain. Thorax 60: 679-682.

Nieberding C, Morand S, Libois R, Michaux JR 2004. A parasite reveals cryptic phylogeographic history of its host. Proc Biol Sci 271: $2559-2568$.

Nieberding CM, Olivieri I 2007. Parasites: proxies for host genealogy and ecology? Trends Ecol Evol 22: 156-165.

Rambaut A 2002. Se-Al: Sequence Alignment Editor, version 2.0 alpha 11 Carbon. [Computer program] Univ. Oxford, UK. Available from: http://tree.bio.ed.ac.uk/software/seal/.

Russel AL, Medellin RA, Mccracken GF 2005. Genetic variation and migration in the Mexican freetailed bat (Tadarida braziliensis mexicana). Mol Ecol 14: 2207-2222.

Soulez B, Palluault F, Cesbron JY, Dei-Cas E, Capron A, Camus D 1991. Introduction of Pneumocystis carinii in a colony of SCID mice. J Protozool 38 (Suppl.): 123S-125S.

Swofford DL 2001. PAUP*: Phylogenetic Analysis Using Parsimony (*and other methods) v4.0b10. Sinauer Associates Inc, Sunderland, Massachusetts.

Taylor ML, Chávez-Tapia CB, Rojas-Martínez A, del Rocio ReyesMontes M, del Valle MB, Zúñiga G 2005. Geographical distribution of genetic polymorphism of the pathogen Histoplasma capsulatum isolated from infected bats captured in a central zone of Mexico. FEMS Immunol Med Microbiol 45: 451-458.

Thompson JD, Gibson TJ, Plewniak F, Jeanmougin F, Higgins DG 1997. The Clustal X windows interface: flexible strategies for multiple sequence alignment aided by quality analysis tools. Nucleic Acids Res 25: 4876-4882.

Tsolaki AG, Beckers P, Wakefield AE 1998. Pre-AIDS era isolates of Pneumocystis carinii f. sp. hominis: high genotypic similarity with contemporary isolates. J Clin Microbiol 36: 90-93.

Wakefield AE 1996. DNA sequences identical to Pneumocystis carinii f. sp. carinii and Pneumocystis carinii f. sp. hominis in samples of air spora. J Clin Microbiol 34: 1754-1759.

Wakefield AE 1998. Genetic heterogeneity in human-derived Pneumocystis carinii. FEMS Immunol Med Microbiol 22: 59-65.

Wakefield AE, Fritscher CC, Malin AS, Gwanzura L, Hughes WT, Miller RF 1994. Genetic diversity in human-derived Pneumocystis carinii isolates from four geographical locations shown by analysis of mitochondrial rRNA gene sequences. J Clin Microbiol 32: 2959-2961.

Wakefield AE, Pixley FJ, Banerji S, Sinclair K, Miller RF, Moxon ER, Hopkin JM 1990. Detection of Pneumocystis carinii with DNA amplification. Lancet 336: 451-453.

Walzer PD, Schnelle V, Armstrong D, Rosen PP 1977. Nude mouse: a new experimental model for Pneumocystis carinii infection. Science 197: 177-179.

Yoshida Y 1989. Ultrastrutural studies of Pneumocystis carinii. J Protozool 36: 53-60. 